\title{
Use of Antidepressants and Risk of Cutaneous Melanoma: A Prospective Registry-Based Case-Control Study
}

This article was published in the following Dove Press journal:

Clinical Epidemiology

\section{Leon Alexander Mclaren \\ Berge $^{1,2}$ \\ Bettina Kulle Andreassen ' \\ Jo S Stenehjem (iD) ${ }^{1-3}$ \\ Trond Heir ${ }^{4,5}$ \\ Kari Furu (iD ${ }^{6}$ \\ Asta Juzeniene ${ }^{7}$ \\ Ingrid Roscher ${ }^{8}$ \\ Inger Kristin Larsen ${ }^{9}$ \\ Adele C Green (ID) 10,II \\ Marit B Veierød (iD ${ }^{2}$ \\ Trude E Robsahm (iD) \\ 'Department of Research, Cancer Registry of Norway, Oslo, Norway; ${ }^{2}$ Oslo Centre for Biostatistics and Epidemiology, Department of Biostatistics, Institute of Basic Medical Sciences, University of Oslo, Oslo, Norway; ${ }^{3}$ Division of Emergencies and Critical Care, Oslo University Hospital, Oslo, Norway; ${ }^{4}$ Institute of Clinical Medicine, Faculty of Medicine, University of Oslo, Oslo, Norway; ${ }^{5}$ Oslo Ischemia Study, Oslo University Hospital, Oslo, Norway; ${ }^{6}$ Department of Chronic Diseases and Ageing, Norwegian Institute of Public Health, Oslo, Norway; \\ ${ }^{7}$ Department of Radiation Biology, Institute for Cancer Research, Oslo University Hospital, Oslo, Norway; ${ }^{8}$ Department of Rheumatology, Dermatology and Infectious Diseases, Oslo University Hospital, Oslo, Norway; 'Department of Registration, Cancer Registry of Norway, Oslo, Norway; ${ }^{10}$ QIMR Berghofer Medical Research Institute, Brisbane, Australia; " ${ }^{\text {CRUK }}$ Manchester Institute, University of \\ Manchester, Manchester, UK}

Correspondence: Leon Alexander Mclaren Berge

Cancer Registry of Norway, P.O. Box

5313 Majorstuen, Oslo N-0304, Norway

$\mathrm{Tel}+4799605034$

Email Leon.Berge@kreftregisteret.no
Purpose: Melanoma is the cancer with the most rapidly rising incidence rate in Norway. Although exposure to ultraviolet radiation (UVR) is the major environmental risk factor, other factors may also contribute. Antidepressants have cancer inhibiting and promoting side effects, and their prescription rates have increased in parallel with melanoma incidence. Thus, we aimed to prospectively examine the association between use of antidepressants and melanoma by using nation-wide data from the Cancer Registry of Norway, the National Registry, the Norwegian Prescription Database and the Medical Birth Registry of Norway.

Patient and Methods: All cases aged 18-85 with a primary cutaneous invasive melanoma diagnosed during 2007-2015 $(n=12,099)$ were matched to population controls 1:10 $(n=118,467)$ by sex and year of birth using risk-set sampling. We obtained information on prescribed antidepressants and other potentially confounding drug use (2004-2015). Conditional logistic regression was used to estimate adjusted rate ratios (RRs) and $95 \%$ confidence intervals (CIs) for the association between overall and class-specific use of antidepressants and incident melanoma. Results: Compared with $\leq 1$ prescription, $\geq 8$ prescriptions of antidepressants overall were negatively associated with melanoma (RR 0.81 CI $0.75-0.87$ ). Class-specific analyses showed decreased RRs for selective serotonin reuptake inhibitors (RR 0.82 CI 0.73-0.93) and mixed antidepressants (RR 0.77 CI 0.69-0.86). The negative association was found for both sexes, age $\geq 50$ years, residential regions with medium and highest ambient UVR exposure, all histological subtypes, trunk, upper and lower limb sites and local disease.

Conclusion: Use of antidepressants was associated with decreased risk of melanoma. There are at least two possible explanations for our results; cancer-inhibiting actions induced by the drug and less UVR exposure among the most frequent users of antidepressants.

Keywords: antidepressants, melanoma, prescription drugs, pharmacoepidemiology, registrybased

\section{Summary}

Melanoma incidence rates are high and rising in many fair-skinned populations, and are mostly caused by excessive sun exposure. However, use of prescribed drugs may influence the risk as some drugs can affect both skin sensitivity to sun exposure and immune responses. Antidepressants are shown to have effects that can inhibit or promote cancer development and the prescription rates have increased in parallel with melanoma rates. We therefore aimed to study the use of antidepressants and melanoma risk.

Compared to non-users, the most frequent users had decreased melanoma risk that was found for both sexes, though the decrease was greater in men, for ages $\geq 50$ years, in regions with the highest ambient ultraviolet radiation (UVR) exposure, for all histological 
subtypes, for all body sites except the head and neck and for local disease. There are at least two possible explanations for our results; anti-cancer actions of antidepressants and less sun exposure among the most frequent users of antidepressants.

\section{Introduction}

The incidence of cutaneous melanoma (hereafter melanoma) is increasing in Caucasian populations worldwide. Since the year 2000 , melanoma has become the most rapidly growing malignancy in Norway, ${ }^{1}$ which ranks amongst the top five countries worldwide in age-standardized melanoma incidence and mortality rates. ${ }^{2}$ Approximately three-quarters of all melanoma cases are estimated to be attributable to ultraviolet radiation (UVR) exposure. ${ }^{3}$ However, the development of melanoma is a multifactorial process which also depends on individual susceptibility, including skin sensitivity to UVR and number of nevi. ${ }^{4}$ Other factors such as previous melanoma diagnosis, ${ }^{5}$ family history of melanoma, ${ }^{6}$ body anthropometry, ${ }^{7}$ hormonal factors ${ }^{8}$ and alcohol consumption ${ }^{9}$ have also been implicated. In addition, a comprehensive European case-control study found that stress, traumatic events and depression were significantly associated with increased melanoma risk. ${ }^{10}$ Possible causal associations could result from the biological effects of stress, which promotes cancer development, ${ }^{11,12}$ or from associated use of antidepressants. Over the last decades, prescription of antidepressants has increased in several countries, ${ }^{13,14}$ including in Norway. ${ }^{15,16}$ Results from preclinical studies show both cancer-promoting and inhibiting side effects of antidepressant agents, ${ }^{17-19}$ raising the question of whether the use of such drugs influences cancer risk.

Observational studies in humans have examined the associations between antidepressant use and several cancers. Early studies indicated a positive association for some cancers, while the predominant finding in more recent studies indicates a negative association. ${ }^{18}$ For melanoma, preclinical studies indicate inhibiting side-effects of antidepressant agents. ${ }^{20-22}$ Though observational population-based studies concerning this relationship appear to be lacking. ${ }^{23,24}$ Thus, in this nationwide case-control study we aimed to prospectively examine the association between use of antidepressants and melanoma development, to assess whether such use might influence the melanoma rate.

\section{Materials and Methods}

The study has a nested case-control design and uses nationwide population-based registry data that includes the entire Norwegian population, aged $18-85$, in the time period 2004-2015 (3.9 million people). The data were obtained from the Cancer Registry of Norway (CRN), the Norwegian Prescription Database (NorPD), the National Registry and the Medical Birth Registry of Norway. Data were linked using the unique personal identification numbers (PIN) assigned to all Norwegian residents. The study design and data collection have been described in detail previously. ${ }^{25}$

\section{Selecting Cases and Controls}

The CRN has recorded cancer diagnoses compulsorily by law since 1953 , and the completeness exceeds $98 \%{ }^{1}$ We obtained information about all melanoma cases in the age group 18-85 years that were diagnosed with a first primary melanoma during 2007-2015 $(n=12,099)$. In the $\mathrm{CRN}$, cancer diagnosis is registered according to the International Classification of Diseases (ICD) of oncology 3rd edition (ICD-O-3) and reported according to the ICD 10th Revision (C43). Tumor site registered according to ICD-7 was categorized as head/ neck (190.0), trunk (190.1, 190.7), upper limb (190.2), lower limb $(190.3,190.4)$, other $(190.5,190.6,190.8)$ and unspecified (190.9). Histological subtype (registered according to the ICD-O-3) was categorized as superficial spreading melanoma (SSM; 87433), nodular melanoma (NM; 87213) and other subtypes (87423, 87443, 87453/87803/87613, including unspecified 87203). Lastly, based on information about metastases, CRN records stage at diagnosis as local disease (no metastases), regional metastasis (metastases in regional lymph nodes, satellites and in transit metastases), distant metastasis (organ metastases and non-regional lymph node metastases) and unspecified. Utilizing risk set sampling, 10 controls for each case were matched on sex and year of birth $(\mathrm{n}=118,467)$. Controls had to be alive, residents in Norway and free of cancer at the date of diagnosis for their respective cases (index date), though could develop cancer thereafter.

\section{Assessment of Antidepressant Use}

The NorPD records all prescribed medications dispensed at Norwegian pharmacies to non-institutionalized individuals since $01.01 .2004 .^{26}$ Drugs dispensed are classified according to the international Anatomical Therapeutic Chemical (ATC) classification system. ${ }^{27} \mathrm{~A}$ record of each dispensation is made with information about the patient, prescriber and medication. ${ }^{26}$ Information in our study from 2004-2015 includes the ATC classification code and defined daily doses (DDD) dispensed per prescription in accordance with the World Health Organization Collaborating Centre for Drug Statistics Methodology. Antidepressants were defined as any drug included in the ATC group N06A and 
classified as selective serotonin reuptake inhibitors (SSRI; N06AB), tricyclic antidepressants (TCAs; N06AA) and other antidepressants (N06AF, N06AG and N06AX). Use of antidepressants from more than one class was defined as mixed use.

Use of antidepressants was categorized according to number of prescriptions: $\leq 1$ prescription, $2-7$ prescriptions and $\geq 8$ prescriptions. The prescriptions may have been obtained at separate or the same dates. Cumulative dose was quantified for each individual based on the total number of DDDs and categorized as non-users and in quartiles (1-91 DDD; 92-365 DDD; 366-1460 DDD; $\geq 1461$ DDD) for the whole sample, for antidepressants overall and for each class of antidepressant. Duration of use was defined as the time between the first and last prescription for each individual, and categorized as $\leq 5$ years and $>5$ years.

To reduce the possible impact of reverse causation, prescriptions of antidepressants dispensed within a year prior to the date of diagnosis (cases)/index date (controls) were disregarded, as well as prescriptions dispensed after the diagnosis/index date.

\section{Potential Confounders}

Certain drugs that affect skin sensitivity to UVR or immune mechanisms could influence the risk of melanoma. ${ }^{28-31}$ To take use of other drugs into account, information about ever use of immunosuppressive drugs (yes/no), ever use of cardiovascular drugs (yes/no) and $>1$ prescription dispensed of other drugs (yes/no) were obtained from NorPD.

The UVR doses increase from northern to southern Norway. Information about the region of residence was obtained from the CRN (cases) and NorPD (controls) and categorized according to cumulative doses of ambient UVR exposure. ${ }^{32}$ First in a five-level variable: northern Norway, central Norway, southwestern Norway, southeast inland, and southeast coast. ${ }^{7}$ In addition, we categorized it in a three-level variable as low (northern Norway), medium (western and central Norway) and highest (eastern and southern Norway). ${ }^{33}$ Cases and controls without information about the place of residence were excluded (67 cases and 3257 controls).

Number of children has been inversely associated with melanoma risk, suggesting a potential role of female sex hormones, ${ }^{34,35}$ or of factors related to parity like socioeconomic status and sunbathing habit. ${ }^{34}$ Thus, information about number of children (prior to diagnosis/index date) for all women was obtained from the Medical Birth Registry and categorized as $0,1-3$ and $>3$ children.
Permission to conduct the study was provided by the Norwegian Data Inspectorate, the Regional Committees for Medical and Health Research Ethics and each of the registries that contributed data.

\section{Statistical Analyses}

Conditional logistic regression was used to assess the relation between antidepressant use and melanoma risk. Rate ratios (RRs) with 95\% confidence intervals (CIs) were estimated, as the collection of controls was done by risk-set sampling. ${ }^{36}$ Stratified analyses were also performed by classes of antidepressant prescribed (SSRI, TCAs, other and mixed). All analyses were adjusted for sex and birth year by design, for use of other drugs and residential ambient UVR region. For women, analyses were conducted with and without adjustment for number of children, but the multivariable results are presented without this additional adjustment, since the difference in results was negligible.

To test for trends in prescription number and cumulative dose, the median of each category was used. We tested for interactions between number of prescriptions and the relevant variables: sex, age at diagnosis/index date, ambient UVR region (in three categories) and number of children (for women only) with a likelihood ratio test. Stratified analyses were directed by prior biological and statistical knowledge. RRs were also estimated for the association between number of antidepressant prescriptions and melanoma, stratified by sex, age at diagnosis/index date and residential ambient UVR exposure. Furthermore, we estimated RRs for the associations between number of antidepressant prescriptions and melanoma site, histological subtype, and clinical stage at diagnosis.

In supplementary analyses, RRs were estimated for the association between melanoma and duration of use with a short ( $\leq 5$ years) and long ( $>5$ years) timeframe, and for the associations between melanoma subtype and number of prescriptions by antidepressant classes.

All statistical analyses were conducted using the statistical software package $\mathrm{R}$ (version 3.5.1). ${ }^{37}$ The significance level was set to $5 \%$, and all tests were two-sided.

\section{Results}

The final study sample consisted of 130,566 individuals. This included 5985 male and 6114 female melanoma cases diagnosed during 2007-2015 with 58,269 and 60,198 population controls, respectively. The majority of cases and controls were $\geq 50$ years of age and resided in the southern/eastern region of Norway (Table 1). Most tumors were located at the 
Table I Characteristics of Cases and Controls in the Study Cohort

\begin{tabular}{|c|c|c|}
\hline Characteristics & $\begin{array}{l}\text { Cases } \\
(n=\mid 2,099) \\
\text { No. }(\%)\end{array}$ & $\begin{array}{l}\text { Controls } \\
(n=118,467) \\
\text { No. (\%) }\end{array}$ \\
\hline \multicolumn{3}{|l|}{ Sex } \\
\hline Men & $5985(49.5)$ & $58,269(49.2)$ \\
\hline Women & $6114(50.5)$ & $60,198(50.8)$ \\
\hline \multicolumn{3}{|l|}{ Age at Diagnosis/Index Date, Years } \\
\hline$<50$ & $3160(26.1)$ & $30,319(25.6)$ \\
\hline $50-69$ & $5615(46.4)$ & $55,236(46.6)$ \\
\hline$\geq 70$ & $3324(27.5)$ & $32,912(27.8)$ \\
\hline \multicolumn{3}{|l|}{ Residential Ambient UVR } \\
\hline \multicolumn{3}{|l|}{ Exposure } \\
\hline Low (northern Norway) & $716(5.9)$ & $11,895(10.0)$ \\
\hline Medium (central/western Norway) & $1724(14.3)$ & $19,429(16.4)$ \\
\hline Highest (southern/eastern Norway) & $9659(79.8)$ & $87,143(73.6)$ \\
\hline \multicolumn{3}{|l|}{ Parity (Women Only) } \\
\hline No children & $|86|(30.4)$ & $18,984(31.5)$ \\
\hline I-3 children & $3894(63.7)$ & $36,901(61.3)$ \\
\hline$>3$ children & $359(5.9)$ & $4313(7.2)$ \\
\hline \multicolumn{3}{|l|}{ Tumor Site } \\
\hline Head/neck & $1314(10.9)$ & - \\
\hline Trunk & $5657(46.7)$ & - \\
\hline Upper limb & $1559(12.9)$ & - \\
\hline Lower limb & $2867(23.7)$ & - \\
\hline Other sites & $52(0.4)$ & - \\
\hline Unspecified site & $650(5.4)$ & - \\
\hline \multicolumn{3}{|l|}{ Histological Type } \\
\hline Superficial spreading melanoma & $6654(55.0)$ & - \\
\hline Nodular melanoma & $2076(17.2)$ & - \\
\hline Other & $3369(27.8)$ & - \\
\hline \multicolumn{3}{|l|}{ Clinical Stage } \\
\hline Local disease & $9828(81.2)$ & - \\
\hline Regional metastasis & $572(4.7)$ & - \\
\hline Distant metastasis & $635(5.3)$ & - \\
\hline Unspecified & $1064(8.8)$ & - \\
\hline \multicolumn{3}{|l|}{ Use of Antidepressants } \\
\hline \multicolumn{3}{|l|}{ I. Number of Prescriptions } \\
\hline$\leq 1$ & 10,597 (87.6) & 102, $154(86.2)$ \\
\hline $2-7$ & $663(5.5)$ & $6612(5.6)$ \\
\hline$\geq 8$ & $839(6.9)$ & $9701(8.2)$ \\
\hline \multicolumn{3}{|l|}{ II. By Antidepressant Classes } \\
\hline Non-user ${ }^{\mathrm{b}}$ & $10,185(84.2)$ & $97,823(82.6)$ \\
\hline SSRI $^{c}$ & $699(5.8)$ & $7358(6.2)$ \\
\hline$T C A^{d}$ & $375(3.1)$ & $3749(3.2)$ \\
\hline Other ${ }^{e}$ & $317(2.6)$ & $3486(2.9)$ \\
\hline Mixed $^{f}$ & $523(4.3)$ & $605 I(5.1)$ \\
\hline \multicolumn{3}{|l|}{ III. By Cumulative Dose, DDD } \\
\hline 0 & $10,185(84.2)$ & $97,823(82.6)$ \\
\hline
\end{tabular}

(Continued)
Table I (Continued).

\begin{tabular}{|c|c|c|}
\hline Characteristics & $\begin{array}{l}\text { Cases } \\
(n=12,099) \\
\text { No. }(\%)\end{array}$ & $\begin{array}{l}\text { Controls } \\
(n=1 \mid 8,467) \\
\text { No. (\%) }\end{array}$ \\
\hline $\begin{array}{l}|-9| \\
92-365 \\
366-\mid 460 \\
\geq|46|\end{array}$ & $\begin{array}{l}524(4.3) \\
454(3.8) \\
508(4.2) \\
428(3.5)\end{array}$ & $\begin{array}{l}5630(4.8) \\
4764(4.0) \\
5239(4.4) \\
5011(4.2)\end{array}$ \\
\hline $\begin{array}{l}\text { Ever Use of Other Drugs } \\
\text { Immunosuppressant drugs }{ }^{h} \\
\text { Cardiovascular drugs }^{\text {h }} \\
\text { Other drugs' }\end{array}$ & $\begin{array}{l}1862(15.4) \\
595 \mid(49.2) \\
5379(44.5)\end{array}$ & $\begin{array}{l}I 8,5 \mid I(I 5.6) \\
57,264(48.3) \\
53,033(44.8)\end{array}$ \\
\hline
\end{tabular}

Notes: ${ }^{a} U$ ltraviolet radiation; ${ }^{b} 0$ prescription; ' $\mathrm{C}$ Selective serotonin reuptake inhibitors (N06AB); ${ }^{\mathrm{d} T r i c y c l i c}$ antidepressants (N06AA); ${ }^{\mathrm{e} O t h e r}$ antidepressants (N06AF, N06AG and N06AX); ${ }^{f}$ Use of more than one class of antidepressants; ${ }^{8}$ Defined daily dose; 'Includes mixed use with other drugs; 'Includes use of other drugs than immunosuppressant or cardiovascular drugs.

trunk (47\%) and lower limb (24\%). SSM was the most common histological subtype (55\%), and the majority were diagnosed in a local stage (81\%).

The overall use of antidepressants was $12 \%$ among cases and $14 \%$ among controls. Women represented half the proportion of users overall (51\% among cases and $51 \%$ among controls) but represented a higher proportion in those with $\geq 8$ prescriptions (69\% and 66\%, respectively) and 2-7 prescriptions (63\% and $61 \%$, respectively). The most commonly prescribed antidepressant class was SSRIs (51\%), where escitalopram (44\%) was the most common drug.

When compared with $\leq 1$ prescription, $\geq 8$ prescriptions of any type of antidepressants were associated with a $19 \%$ reduced risk of melanoma with a negative trend (Table 2). Analysis stratified by duration of use showed significantly lower risk for $2-7$ prescriptions (RR $0.5295 \%$ CI $0.38-0.74$ ) and $\geq 8$ prescriptions (RR $0.7995 \%$ CI $0.72-0.87$ ) among longterm users ( $>5$ years). Significantly lower risk was only found for $\geq 8$ prescriptions (RR $0.8295 \%$ CI 0.74-0.92) among shortterm users ( $\leq 5$ years) (Supplementary Table S1). Analyses stratified by antidepressant classes showed an $18 \%$ and $23 \%$ lower melanoma risk for persons with $\geq 8$ prescriptions of SSRIs and mixed antidepressants, respectively, compared to $\leq 1$ prescription (Table 2 ). For the class of other antidepressants, a significantly negative trend was seen, despite non-significant effect estimates, while for TCA, no associations were found.

Compared to the lowest quartile of cumulative dose (1-91 DDD), no significant association with melanoma risk was found for increasing quartiles (Table 3). However, a significant trend was found and non-use (0 DDD) was associated with a $15 \%$ increased risk. In addition, a reduced 
Table 2 Rate Ratios (RRs) with 95\% Confidence Intervals (Cls) for Melanoma Incidence by Number of Prescriptions of Antidepressants Overall and Stratified by Class of Antidepressants

\begin{tabular}{|c|c|c|c|}
\hline $\begin{array}{l}\text { Number of } \\
\text { Prescriptions }\end{array}$ & No. Case/Controls & $\operatorname{RR}(95 \% \mathrm{Cl})^{\mathbf{a}}$ & $\mathbf{P}_{\text {trend }}{ }^{\mathbf{f}}$ \\
\hline \multicolumn{4}{|l|}{ Overall } \\
\hline$\leq 1$ & $10,597 / 102,154$ & 1.00 (reference) & \\
\hline $2-7$ & $663 / 6612$ & $0.94(0.87,1.03)$ & \\
\hline$\geq 8$ & $839 / 9701$ & $0.8 \mathrm{I}(0.75,0.87)$ & $<0.001$ \\
\hline \multicolumn{4}{|c|}{ By Antidepressant Classes } \\
\hline \multicolumn{4}{|l|}{ SSRI' } \\
\hline$\leq 1$ & $4736 / 45,455$ & 1.00 (reference) & \\
\hline$\geq 8$ & $289 / 3280$ & $0.82(0.73,0.93)$ & 0.003 \\
\hline \multicolumn{4}{|l|}{ TCA $^{c}$} \\
\hline$\leq 1$ & $2782 / 26,637$ & 1.00 (reference) & \\
\hline$\geq 8$ & $107 / 1100$ & $0.90(0.73,1.10)$ & 0.295 \\
\hline \multicolumn{4}{|l|}{ Other ${ }^{d}$} \\
\hline$\leq 1$ & $2679 / 25,576$ & 1.00 (reference) & \\
\hline$\geq 8$ & $84 / 967$ & $0.8 \mathrm{I}(0.65, \mathrm{I} .02)$ & 0.036 \\
\hline \multicolumn{4}{|l|}{ Mixed $^{\mathrm{e}}$} \\
\hline$\leq 1$ & $3838 / 36,528$ & 1.00 (reference) & \\
\hline$\geq 8$ & $359 / 4354$ & $0.77(0.69,0.86)$ & $<0.001$ \\
\hline
\end{tabular}

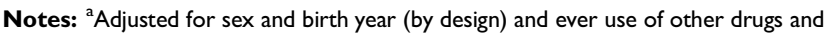
residential ambient ultraviolet radiation; 'belective serotonin reuptake inhibitors (N06AB); 'Tricyclic antidepressants (N06AA); 'Other antidepressants (N06AF, N06AG and N06AX); ${ }^{\mathrm{e}}$ Use of more than one class of antidepressants; ${ }^{\text {fTrend }}$ test uses the median number of prescriptions for all prescription categories $(\leq 1 ; 2-7 ; \geq 8)$.

risk was found per increment of 100 DDD overall $\left(\mathrm{P}_{\text {trend }}\right.$ 0.001) (not shown). When stratifying by classes of antidepressants, no significant associations were found, except for a $69 \%$ increased risk among non-users and a $65 \%$ increased risk for a cumulative dose of 92-365 DDD when compared to the lowest DDD quartile of mixed antidepressant use (Table 3).

Compared to $\leq 1$ prescription, those with $\geq 8$ prescriptions of antidepressants had a significantly decreased risk of melanoma for specified tumor sites except the head and neck, other and unspecified sites (Table 4 ). Moreover, $\geq 8$ prescriptions were associated with a decreased risk of all melanoma subtypes, with significant negative trends $\left(\mathrm{P}_{\text {trend }}<0.001\right.$ (SSM); 0.017 (NM); 0.013 (other)). Supplementary analyses, stratified by antidepressant classes, showed that $\geq 8$ prescriptions of SSRIs were associated with a decreased risk of SSM (RR 0.81 95\% CI 0.69-0.96). Mixed antidepressants were associated with a decreased risk of SSM (RR 0.75 95\% CI 0.65-0.87) and NM (RR $0.70 \quad 95 \%$ CI $0.52-0.94)$. (Supplementary Table S2). Lastly, $\geq 8$ prescriptions of
Table 3 Rate Ratios (RRs) with 95\% Confidence Intervals (Cls) for Melanoma Incidence by Quartiles (Q) of Cumulative Defined Daily Dose (DDD) of Antidepressants Overall and Stratified by Class of Antidepressants

\begin{tabular}{|c|c|c|c|}
\hline $\begin{array}{l}\text { Cumulative Dose, } \\
\text { DDD }\end{array}$ & $\begin{array}{l}\text { No. Casel } \\
\text { Controls }\end{array}$ & $\operatorname{RR}(95 \% \mathrm{Cl})^{\mathbf{a}}$ & $P_{\text {trend }}{ }^{\mathbf{f}}$ \\
\hline \multicolumn{4}{|l|}{ Overall } \\
\hline 0 & $10,185 / 97,823$ & $1.15(1.04,1.26)$ & \\
\hline QI (DDD I-9I) & $524 / 5630$ & I (Reference) & \\
\hline Q2 (DDD 92-365) & $454 / 4764$ & $1.03(0.90,1.17)$ & \\
\hline Q3 (DDD 366-1460) & $508 / 5239$ & $1.04(0.91,1.18)$ & \\
\hline Q4 (DDD $\geq|46|)$ & $428 / 5011$ & $0.91(0.80,1.04)$ & $<0.001$ \\
\hline \multicolumn{4}{|c|}{ By Antidepressant Classes } \\
\hline \multicolumn{4}{|l|}{ SSRI $\mathbf{I}^{\mathrm{b}}$} \\
\hline 0 & $4617 / 44,077$ & $1.24(0.99,1.55)$ & \\
\hline QI (DDD I-9I) & $88 / 1030$ & I (Reference) & \\
\hline Q2 (DDD 92-365) & $210 / 2171$ & $1.12(0.86,1.46)$ & \\
\hline Q3 (DDD 366-1460) & $237 / 2227$ & $1.23(0.95,1.59)$ & \\
\hline Q4 (DDD $\geq|46|)$ & $164 / 1930$ & $0.99(0.75,1.28)$ & 0.007 \\
\hline \multicolumn{4}{|l|}{ TCA $^{\mathrm{c}}$} \\
\hline 0 & $2628 / 25,104$ & $1.08(0.94,1.23)$ & \\
\hline QI (DDD I-9I) & $242 / 2432$ & I (Reference) & \\
\hline Q2 (DDD 92-365) & $57 / 619$ & $0.92(0.68,1.25)$ & \\
\hline Q3 (DDD 366-1460) & $60 / 550$ & $1.09(0.81,1.47)$ & \\
\hline Q4 (DDD $\geq|46|)$ & $16 / 148$ & $1.07(0.62,1.83)$ & 0.906 \\
\hline \multicolumn{4}{|l|}{ Other ${ }^{d}$} \\
\hline 0 & $2540 / 24,156$ & I.II $(0.94,1.3 \mathrm{I})$ & \\
\hline QI (DDD I-9I) & $164 / 1714$ & I (Reference) & \\
\hline Q2 (DDD 92-365) & $60 / 781$ & $0.79(0.58,1.07)$ & \\
\hline Q3 (DDD 366-1460) & $56 / 555$ & $1.05(0.76,1.46)$ & \\
\hline Q4 (DDD $\geq|46|)$ & $37 / 436$ & $0.87(0.60,1.27)$ & 0.077 \\
\hline \multicolumn{4}{|l|}{ Mixed $^{\mathrm{e}}$} \\
\hline 0 & $3838 / 36,528$ & $1.69(1.16,2.45)$ & \\
\hline QI (DDD I-9I) & $30 / 454$ & I (Reference) & \\
\hline Q2 (DDD 92-365) & $127 / \mid 193$ & $1.65(1.09,2.50)$ & \\
\hline Q3 (DDD 366-1460) & I55/1907 & $1.28(0.85,1.92)$ & \\
\hline Q4 (DDD $\geq|46|)$ & $211 / 2497$ & $1.33(0.89,1.98)$ & 0.103 \\
\hline
\end{tabular}

Notes: ${ }^{a}$ Adjusted for sex and birth year (by design) and ever use of other drugs and residential ambient ultraviolet radiation; 'Selective serotonin reuptake inhibitors

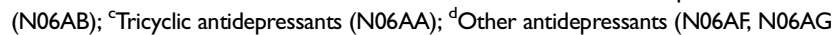
and N06AX); ${ }^{\mathrm{e}}$ Use of more than one class of antidepressants; ${ }^{\mathrm{T}}$ Trend test uses the median defined daily dosage for all quartiles (0; I-91; 92-365; 366-|460; $\geq|46|$ ).

antidepressants were associated with a $21 \%$ decreased risk for local stage melanoma, while no associations were found for other stages (Table 4).

Compared to $\leq 1$ prescription, men and women with $\geq 8$ prescriptions of any antidepressant had $27 \%$ and $14 \%$ reduced risk of melanoma, respectively ( $\left.P_{\text {interaction }} 0.029\right)$ (Table 5). No association was found for the youngest age group ( $<50$ years), while a $24 \%$ and $21 \%$ reduced melanoma risk was found in the age groups 50-69 and $\geq 70$ years, 
Table 4 Rate Ratios (RRs) with 95\% Confidence Intervals (Cls) of Melanoma Incidence for $\geq 8$ Prescriptions of Antidepressants versus $\leq \mathrm{I}$ Prescription, Stratified by Tumor Site, Histological Type, and Clinical Stage at Diagnosis

\begin{tabular}{|c|c|c|c|}
\hline & \multirow[t]{2}{*}{$\begin{array}{l}\text { No. Case/ } \\
\text { Controls }\end{array}$} & \multicolumn{2}{|c|}{$\begin{array}{l}\geq 8 \text { Prescriptions vs } \leq 1 \\
\text { Prescription }\end{array}$} \\
\hline & & $\operatorname{RR}(95 \% \mathrm{Cl})^{\mathbf{a}}$ & $\mathbf{P}_{\text {trend }}{ }^{\mathrm{e}}$ \\
\hline \multicolumn{4}{|l|}{ Tumor Site } \\
\hline Head/neck & $13|4 / 12,8| 8$ & $0.93(0.75,1.15)$ & 0.468 \\
\hline Trunk & $5657 / 55,032$ & $0.79(0.70,0.88)$ & $<0.001$ \\
\hline Upper limb & $|559 / 15,18|$ & $0.80(0.66,0.97)$ & 0.022 \\
\hline Lower limb & $2867 / 27,962$ & $0.76(0.65,0.88)$ & $<0.001$ \\
\hline Other & $52 / 511$ & $0.99(0.37,2.64)$ & 0.997 \\
\hline Unspecified & $650 / 6354$ & $1.07(0.79,1.45)$ & 0.780 \\
\hline \multicolumn{4}{|l|}{ Histological Type } \\
\hline SSM $^{\mathrm{b}}$ & $6654 / 64,763$ & $0.80(0.73,0.89)$ & $<0.001$ \\
\hline$N^{c}$ & $2076 / 20,282$ & $0.80(0.67,0.96)$ & 0.017 \\
\hline Other $^{d}$ & $3369 / 32,813$ & $0.83(0.72,0.96)$ & 0.013 \\
\hline \multicolumn{4}{|l|}{ Clinical Stage } \\
\hline Local disease & $9828 / 95,725$ & $0.79(0.73,0.86)$ & $<0.001$ \\
\hline Regional metastasis & $572 / 5569$ & $0.89(0.64,1.24)$ & 0.438 \\
\hline Distant metastasis & $635 / 6209$ & $0.91(0.65,1.27)$ & 0.559 \\
\hline Unspecified & $1064 / 10,328$ & $0.98(0.75,1.28)$ & 0.982 \\
\hline
\end{tabular}

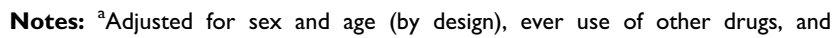
residential ambient ultraviolet radiation; 'Superficial spreading melanoma; 'Nodular melanoma; 'Includes all other histological types; 'Trend test uses the median number of prescriptions in all three prescription categories $(\leq 1 ; 2-7 ; \geq 8)$.

respectively $\left(\mathrm{P}_{\text {interaction }} 0.013\right)$. In the residential regions with medium and highest ambient UVR, $\geq 8$ prescriptions were associated with a $27 \%$ and $18 \%$ reduced melanoma risk, respectively, while no association was found in the low UVR region ( $\mathrm{P}_{\text {interaction }}$ 0.379). Analyses using the fivelevel variable of residential ambient UVR exposure gave similar results to that with three-levels (not shown). We found no significant interaction with parity $\left(P_{\text {interaction }} 0.248\right)$.

\section{Discussion}

Based on data from nationwide health registries, we found that $\geq 8$ prescriptions of antidepressants were associated with decreased melanoma risk. Analyses stratified by antidepressant classes showed a significant negative association and trend for SSRIs and mixed antidepressants, as well as a negative trend for the class of other antidepressants. For cumulative dose (DDD), a significant negative trend was found for antidepressant use overall and for SSRIs, despite the effect estimates not supporting a dose-response relationship. The negative association was significant for both sexes, age $\geq 50$ years, in residential
Table 5 Rate Ratios (RRs) with 95\% Confidence Intervals (Cls) of Melanoma Incidence for $\geq 8$ Prescriptions of Antidepressants versus $\leq$ I Prescription, Stratified by Sex, Age at Diagnosis/Index Date and Residential Ambient Ultraviolet Radiation (UVR) Exposure

\begin{tabular}{|c|c|c|}
\hline \multirow[t]{2}{*}{ Variables } & \multicolumn{2}{|c|}{$\begin{array}{l}\geq 8 \text { Prescriptions vs } \leq 1 \\
\text { Prescription }\end{array}$} \\
\hline & RR $(95 \% \mathrm{Cl})$ & $P_{\text {trend }}{ }^{d}$ \\
\hline \multicolumn{3}{|l|}{ Sex ${ }^{a}$} \\
\hline Men & $0.73(0.64,0.83)$ & $<0.001$ \\
\hline Women & $0.86(0.78,0.94)$ & $<0.001$ \\
\hline$P_{\text {interaction }}$ & 0.029 & \\
\hline \multicolumn{3}{|l|}{ Age at Diagnosis/Index Date ${ }^{b}$, Years } \\
\hline$<50$ & $0.99(0.84,1.16)$ & 0.877 \\
\hline $50-69$ & $0.76(0.68,0.85)$ & $<0.001$ \\
\hline$\geq 70$ & $0.79(0.69,0.90)$ & $<0.001$ \\
\hline$P_{\text {interaction }}$ & 0.013 & \\
\hline \multicolumn{3}{|l|}{ Residential Ambient UVR Exposure $^{c}$} \\
\hline Low (northern Norway) & $1.12(0.67,1.86)$ & 0.600 \\
\hline Medium (central/western Norway) & $0.73(0.55,0.95)$ & 0.019 \\
\hline Highest (southern/eastern Norway) & $0.82(0.75,0.89)$ & $<0.001$ \\
\hline$P_{\text {interaction }}$ & 0.379 & \\
\hline
\end{tabular}

Notes: ${ }^{a}$ Adjusted for age (by design), ever use of other drugs and residential ambient UVR exposure; ${ }^{b}$ Adjusted for sex (by design) ever use of other drugs and residential ambient UVR; 'Adjusted for sex and age (by design) and ever use of other drugs; ${ }^{\mathrm{d}}$ Trend test uses the median number of prescriptions in all three prescription categories $(\leq 1 ; 2-7 ; \geq 8)$.

regions with medium and highest ambient UVR exposure, all histological subtypes, tumors at trunk, upper and lower limb, and for localized disease at diagnosis.

Depression and mood disorders may promote cancer processes through several pathways, ${ }^{11,12}$ though the epidemiological evidence for depression being a risk factor for cancer is not strong. ${ }^{38}$ However, a comprehensive European case-control study identified factors of stress, traumatic events and depression as being associated with an increased risk of melanoma. ${ }^{10}$ On the other hand, antidepressants treat depression disorders and are also found to normalize the pathway alterations that occur during depression. ${ }^{11}$ Preclinical studies have raised the question of whether such drugs can influence cancer risk. The predominant findings indicate cancer-inhibitory actions of antidepressants, although cancer-promoting effects have also been observed. ${ }^{18,19}$ It is worth noting though that such studies vary with regard to design and type of antidepressant. It is suggested that antidepressants may affect pathways which inhibit the malignant cell cycle and activates the immune system in ways that trigger apoptosis in 
cancer cells. ${ }^{18,39,40}$ Cancer-inhibiting actions from antidepressants, both SSRIs ${ }^{20,41}$ and TCAs, ${ }^{21}$ are observed for melanoma cells in vivo and in vitro.

Over the last two decades, an increasing number of observational studies have investigated the association between antidepressants and cancer, mainly focusing on breast, ovarian and colon cancer. Results from the first studies suggested a positive association, but over time, the findings predominantly indicated a negative association (mainly for SSRIs). ${ }^{18}$ A previous review found that shortterm and/or low-dose antidepressant use increased the risk of breast and ovarian cancer. ${ }^{42}$ More recently however, a prospective cohort study, within the Nurses' Health Study (USA), found no associations for breast cancer ${ }^{43}$ and a nationwide registry-based case-control study from Denmark found a negative association between SSRIs and epithelial ovarian cancer. ${ }^{44}$

To our knowledge, this is the first observational study investigating the relation between antidepressants and melanoma risk. Our results are in line with the cancer-inhibiting properties exhibited by these drugs in pre-clinical studies, including the more recent observational studies of other cancer types. The different results observed across antidepressant classes however, may be due to different action pathways inherent to each drug ${ }^{45}$ but may also result from small groups and weakened power in stratified analyses.

We found a significant negative association for both sexes, although it seemed to be stronger for men than for women. Reproductive factors and female sex hormones are suggested to play a role in melanoma development. ${ }^{34,35}$ A recent population-based cohort study of Norwegian women found no association between reproductive factors and melanoma risk ${ }^{46}$ and neither did our analyses. Adjusting for number of children (for women only) did not influence the estimates. Regarding menopausal hormone use, a nationwide cohort study based on Finnish data recently reported a significant positive association between menopausal estrogen therapy and melanoma risk. ${ }^{47}$ In our analyses, we have adjusted for other drug use, however, we were not able to separate estrogen use from other drugs.

The elevated risk observed in non-users, compared to the lowest cumulative dose (DDD 1-91), weakens the hypothesis that drug effects explain our findings. Patients with depression are less active in everyday social life, ${ }^{48}$ which might also include activities involving UVR exposure. As far as we know, neither depression nor use of antidepressants has been associated with altered habits of outdoor activity and reduced UVR exposure. Increased use of indoor tanning has been observed, ${ }^{49,50}$ although such studies only involve age groups $<50$ years. If a decrease in social functioning among patients with depression leads to a reduction in UVR exposure, the potential difference in UVR exposure between the healthy and the depressed should be more distinct in areas with higher ambient UVR exposure, which is in line with our result. Thus, our data do not support the use of antidepressants as a preventive measure against melanoma.

In analyses by duration of use, the negative association was significant for both user categories among long-term users ( $>5$ years), but only for the highest user category among short-term users $(<5$ years). Such results are in line with potential cancer-inhibiting actions induced by longterm use or a considerable short-term use of antidepressants. However, if the most depressed are those most affected socially, and represent those treated over a longer timeframe or have a higher number of prescription over a shorter timeframe, then reduced UVR exposure could be a possible explanation.

The main strengths of this study include the use of complete and high-quality data, collected from nationwide registries with mandatory reporting. This approach eliminated selection and recall bias and ensured detailed information about invasive melanoma diagnoses and drug use. Only pre-diagnostic prescriptions of antidepressants were included, and all prescriptions given the year before diagnosis/index date were removed for cases and controls, respectively. Primary non-adherence is not an issue since only information pertaining to drug dispensation and purchase by patients is recorded in the NorPD, and are more indicative of use than prescriptions alone. ${ }^{51}$ In addition, the agreement between filled prescriptions data and selfreported antidepressant medication is reported to be good. ${ }^{52}$

There are also limitations when interpreting the results of this study. We had no information about individual UVR exposure, such as recreational sun exposure, sunburns (as a marker of severe acute UV exposure episodes) and indoor tanning. As the latency time between drug exposure and melanoma diagnosis is uncertain, the followup time might have been insufficient to reveal the true association between use of antidepressants and melanoma risk. Underlying indications for drug use and comorbidities that influence the risk of melanoma may have introduced potential confounding by indication. Although we have adjusted for use of other drug types, we cannot exclude the possibility that different indications for different antidepressant could have produced different estimates 
for the drug classes. Furthermore, different indications may be related to other relevant factors (eg, obesity, socioeconomic factors, hormone use, and alcohol consumption). Unfortunately, we lack information about such potentially confounding factors. In addition, differences in healthcare usage may influence our results, although adjustment for use of other drugs could act as an indicator for this. While the majority of people in Norway live in the southern/ eastern regions, we cannot rule out that access to healthcare and prescription practices may vary between regions.

\section{Conclusions}

The negative associations observed between antidepressant use and melanoma risk can result from at least two possible explanations: cancer-inhibiting actions induced by the drug and less UVR exposure among the most frequent users of antidepressants, compared to non-users. To investigate this further, studies with individual information about UVR exposure and indication for drug use are required.

\section{Abbreviations}

All are defined in full at their first instance in the text: ATC, anatomical therapeutic chemical; $\mathrm{CI}$, confidence interval; $\mathrm{CRN}$, Cancer Registry of Norway; DDD, defined daily doses; ICDO-3, International Classification of Diseases of Oncology 3rd edition; ICD-7/10, International Classification of Diseases 7th/ 10th Revision; NM, nodular melanoma; NorPD, Norwegian Prescription Database; PIN, personal identification number; $\mathrm{RR}$, rate ratio; SSRI, selective serotonin reuptake inhibitor; TCA, tricyclic antidepressants; UVR, ultraviolet radiation.

\section{Ethics Approval and Informed Consent}

The study is approved by the Norwegian Data Protection Authority and the Regional Committee for Medical and Health Research Ethics. The study is also approved by the national registries contributing with data; $\mathrm{CRN}$, the National Registry, NorPD and the Medical Birth Registry. The linkage key for the 11-digit PINs was stored and governed by a third party unavailable to the research team. All data management and analyses were conducted on data with no individual person identified. This casecontrol study utilized only data from nationwide population-based registers and thus did not include a recruitment process for patients, who were not involved in neither the design nor conduct of the study. Thus, the research question and outcome measures were not informed by any specific patient priorities, experiences or preferences. Rather, their formulation was based upon our own priorities for patient benefit and result interpretation. All results are distributed on a group level, without any possibilities for individual identification.

\section{Data Sharing Statement}

The data is available as presented in the paper. According to Norwegian legislation, our approvals to use the data for the current study do not allow us to distribute or make the data directly available to other parties.

\section{Author Contributions}

All authors contributed to data analysis, drafting and revising the article, gave final approval of the version to be published, and agreed to be accountable for all aspects of the work.

\section{Funding}

The study is funded by the South-Eastern Norway Regional Health Authority (no. 16/00451-33).

\section{Disclosure}

The authors report no conflicts of interest in this work.

\section{References}

1. CRN. Cancer in Norway 2016 - Cancer incidence, mortality, survival and prevalence in Norway. Cancer Registry of Norway; 2017. Available from: https://www.kreftregisteret.no/globalassets/cancer-innorway/2016/cin-2106.pdf.

2. Karimkhani C, Green AC, Nijsten T, et al. The global burden of melanoma: results from the Global Burden of Disease Study 2015. Br J Dermatol. 2017;177(1):134-140. doi:10.1111/bjd.15510

3. Arnold M, de Vries E, Whiteman DC, et al. Global burden of cutaneous melanoma attributable to ultraviolet radiation in 2012. Int J Cancer. 2018. doi:10.1002/ijc.31527

4. Berwick M, Buller DB, Cust A, et al. Melanoma epidemiology and prevention. In: Kaufman HL, Mehnert JM, editors. Melanoma. Cham: Springer International Publishing; 2016:17-49.

5. Robsahm TE, Karagas MR, Rees JR, Syse A. New malignancies after squamous cell carcinoma and melanomas: a population-based study from Norway. BMC Cancer. 2014;14(1):210. doi:10.1186/1471-2407$14-210$

6. Hemminki K, Zhang H, Czene K. Familial and attributable risks in cutaneous melanoma: effects of proband and age. J Clin Investig Dermatol. 2003;120(2):217-223. doi:10.1046/j.1523-1747.2003.12041.x

7. Stenehjem JS, Veierod MB, Nilsen LT, et al. Anthropometric factors and cutaneous melanoma: prospective data from the population-based Janus Cohort. Int J Cancer. 2018;142(4):681-690. doi:10.1002/ijc.v142.4

8. De Giorgi V, Gori A, Savarese I, et al. Role of BMI and hormone therapy in melanoma risk: a case-control study. J Cancer Res Clin Oncol. 2017;143(7):1191-1197. doi:10.1007/s00432-017-2387-5

9. Rota M, Pasquali E, Bellocco R, et al. Alcohol drinking and cutaneous melanoma risk: a systematic review and dose-risk meta-analysis. $\mathrm{Br}$ J Dermatol. 2014;170(5):1021-1028. doi:10.1111/bjd.2014.170.issue-5 
10. de Vries E, Trakatelli M, Kalabalikis D, et al. Known and potential new risk factors for skin cancer in European populations: a multicentre case-control study. Br J Dermatol. 2012;167(Suppl 2):1-13. doi:10.1111/bjd.2012.167.issue-s2

11. Maes M, Fisar Z, Medina M, Scapagnini G, Nowak G, Berk M. New drug targets in depression: inflammatory, cell-mediated immune, oxidative and nitrosative stress, mitochondrial, antioxidant, and neuroprogressive pathways. And new drug candidates-Nrf2 activators and GSK-3 inhibitors. Inflammopharmacology. 2012;20(3):127-150.

12. Le CP, Nowell CJ, Kim-Fuchs C, et al. Chronic stress in mice remodels lymph vasculature to promote tumour cell dissemination. Nat Commun. 2016;7:10634. doi:10.1038/ncomms10634

13. Lockhart P, Guthrie B. Trends in primary care antidepressant prescribing 1995-2007: a longitudinal population database analysis. $\mathrm{Br}$ J Gen Pract. 2011;61(590):e565-e572. doi:10.3399/bjgp11X593848

14. Gomez-Lumbreras A, Ferrer P, Ballarin E, et al. Study of antidepressant use in 5 European settings. Could economic, sociodemographic and cultural determinants be related to their use? J Affect Disord. 2019;249:278-285. doi:10.1016/j.jad.2019.01.039

15. NorPD. Statistics from the Norwegian Prescription Database. Norwegian Institute of Public Health; 2019. Available from: http:// www.norpd.no/Prevalens.aspx. Accessed August 7, 2019.

16. Hartz I, Skurtveit S, Hjellvik V, Furu K, Nesvag R, Handal M. Antidepressant drug use among adolescents during 2004-2013: a population-based register linkage study. Acta Psychiatr Scand. 2016;134(5):420-429. doi:10.1111/acps.2016.134.issue-5

17. Daley E, Wilkie D, Loesch A, et al. Chlorimipramine: a novel anticancer agent with a mitochondrial target. Biochem Biophys Res Commun. 2005;328(2):623-632. doi:10.1016/j.bbrc.2005.01.028

18. Frick LR, Rapanelli M. Antidepressants: influence on cancer and immunity? Life Sci. 2013;92(10):525-532. doi:10.1016/j.lfs.2013.01.020

19. Sternbach H. Are antidepressants carcinogenic? A review of preclinical and clinical studies. J Clin Psychiatry. 2003;64(10):1153-1162. doi:10.4088/JCP.v64n1003

20. Grygier B, Arteta B, Kubera M, et al. Inhibitory effect of antidepressants on B16F10 melanoma tumor growth. Pharmacol Rep. 2013;65 (3):672-681. doi:10.1016/S1734-1140(13)71045-4

21. Parker KA, Glaysher S, Hurren J, et al. The effect of tricyclic antidepressants on cutaneous melanoma cell lines and primary cell cultures. Anticancer Drugs. 2012;23(1):65-69. doi:10.1097/CAD. 0b013e32834b1894

22. Reddy KK, Lefkove B, Chen LB, et al. The antidepressant sertraline downregulates Akt and has activity against melanoma cells. Pigment Cell Melanoma Res. 2008;21(4):451-456. doi:10.1111/j.1755-148X. 2008.00481.x

23. Gandini S, Palli D, Spadola G, et al. Anti-hypertensive drugs and skin cancer risk: a review of the literature and meta-analysis. Crit Rev Oncol Hematol. 2018;122:1-9. doi:10.1016/j.critrevonc.2017.12.003

24. Tang H, Fu S, Zhai S, Song Y, Han J. Use of antihypertensive drugs and risk of malignant melanoma: a meta-analysis of observational studies. Drug Saf. 2017;41:161-169.

25. Berge LAM, Andreassen BK, Stenehjem JS, et al. Cardiovascular, antidepressant and immunosuppressive drug use in relation to risk of cutaneous melanoma: a protocol for a prospective case-control study. BMJ Open. 2019;9(2):e025246. doi:10.1136/bmjopen-2018025246

26. Furu K, Wettermark B, Andersen M, Martikainen JE, Almarsdottir AB, Sorensen HT. The Nordic countries as a cohort for pharmacoepidemiological research. Basic Clin Pharmacol Toxicol. 2010;106(2):86-94. doi:10.1111/j.1742-7843.2009.00494.x

27. WHO. Guidelines for ATC Classification and DDD Assignment 2015. Norwegian Institute of Public Health; 2016.

28. Jensen AØ, Thomsen HF, Engebjerg MC, Olesen AB, Sørensen HT, Karagas MR. Use of photosensitising diuretics and risk of skin cancer: a population-based case-control study. Br J Cancer. 2008;99(9): 1522-1528. doi:10.1038/sj.bjc.6604686
29. Monteiro AF, Rato M, Martins C. Drug-induced photosensitivity: photoallergic and phototoxic reactions. Clin Dermatol. 2016;34 (5):571-581. doi:10.1016/j.clindermatol.2016.05.006

30. Pottegard A, Friis S, Sturmer T, Hallas J, Bahmanyar S. Considerations for pharmacoepidemiological studies of drug-cancer associations. Basic Clin Pharmacol Toxicol. 2017;122:451-459.

31. Selvag E. [Drugs and sun]. Tidsskr nor Laegeforen. 2003;123 (13-14):1860-1861.

32. Medhaug I, Olseth JA, Reuder J. UV radiation and skin cancer in Norway. $J$ Photochem Photobiol B. 2009;96(3):232-241. doi:10.1016/j. jphotobiol.2009.06.011

33. Robsahm TE, Tretli S. Cutaneous malignant melanoma in Norway: variation by region of residence before and after the age 17. Cancer Causes Control. 2001;12(6):569-576. doi:10.1023/A:1011287918405

34. Gandini S, Iodice S, Koomen E, Di Pietro A, Sera F, Caini S. Hormonal and reproductive factors in relation to melanoma in women: current review and meta-analysis. Eur J Cancer. 2011;47 (17):2607-2617. doi:10.1016/j.ejca.2011.04.023

35. Karagas MR, Zens MS, Stukel TA, et al. Pregnancy history and incidence of melanoma in women: a pooled analysis. Cancer Causes Control. 2006;17(1):11-19. doi:10.1007/s10552-005-0281-y

36. Pearce N. What does the odds ratio estimate in a case-control study? Int J Epidemiol. 1993;22(6):1189-1192. doi:10.1093/ije/22.6.1189

37. R Core Team (2019).R: A Language and Environment for Statistical Computing. R Foundation for Statistical Computing, Vienna, Austria. Available from: https://www.R-project.org/.

38. Jia Y, Li F, Liu YF, Zhao JP, Leng MM, Chen L. Depression and cancer risk: a systematic review and meta-analysis. Public Health. 2017;149:138-148. doi:10.1016/j.puhe.2017.04.026

39. Dikmen M, Cantürk Z, Öztürk Y. Escitalopram oxalate, a selective serotonin reuptake inhibitor, exhibits cytotoxic and apoptotic effects in glioma C6 cells. Acta Neuropsychiatr. 2011;23(4):173-178. doi:10.1111/j.1601-5215.2011.00550.x

40. Yuan S-Y, Cheng C-L, Ho H-C, et al. Nortriptyline induces mitochondria and death receptor-mediated apoptosis in bladder cancer cells and inhibits bladder tumor growth in vivo. Eur J Pharmacol. 2015;761:309-320. doi:10.1016/j.ejphar.2015.06.007

41. Kirkova M, Tzvetanova E, Vircheva S, Zamfirova R, Grygier B, Kubera M. Antioxidant activity of fluoxetine: studies in mice melanoma model. Cell Biochem Funct. 2010;28(6):497-502. doi:10.1002/cbf.1682

42. Cosgrove L, Shi L, Creasey DE, Anaya-McKivergan M, Myers JA, Huybrechts KF. Antidepressants and breast and ovarian cancer risk: a review of the literature and researchers' financial associations with industry. PLoS One. 2011;6(4):e18210. doi:10.1371/journal.pone.0018210

43. Reeves KW, Okereke OI, Qian J, Tamimi RM, Eliassen AH, Hankinson SE. Depression, antidepressant use, and breast cancer risk in pre- and postmenopausal women: a prospective cohort study. Cancer Epidemiol Biomarkers Prev. 2018;27(3):306-314. doi:10.1158/10559965.EPI-17-0707

44. Mørch LS, Dehlendorff C, Baandrup L, Friis S, Kjaer SK. Use of antidepressants and risk of epithelial ovarian cancer. Int J Cancer. 2017;141(11):2197-2203. doi:10.1002/ijc.v141.11

45. Harlow BL, Cramer DW, Baron JA, Titus-Ernstoff L, Greenberg ER. Psychotropic medication use and risk of epithelial ovarian cancer. Cancer Epidemiol Biomarkers Prev. 1998;7(8):697-702.

46. Stoer NC, Botteri E, Ghiasvand R, et al. Reproductive factors and risk of melanoma: a population-based cohort study. $\mathrm{Br} J$ Dermatol. 2019;181(2):282-289. doi:10.1111/bjd.2019.181.issue-2

47. Botteri E, Stoer NC, Weiderpass E, Pukkala E, Ylikorkala O, Lyytinen H. Menopausal hormone therapy and risk of melanoma: a nationwide register-based study in Finland. Cancer Epidemiol Biomarkers Prev. 2019;28:1857-1860. doi:10.1158/1055-9965.EPI-19-0554

48. Hodgetts S, Gallagher P, Stow D, Ferrier IN, O'Brien JT. The impact and measurement of social dysfunction in late-life depression: an evaluation of current methods with a focus on wearable technology. Int J Geriatr Psychiatry. 2017;32(3):247-255. doi:10.1002/gps.4632 
49. Gillen MM, Markey CN. The role of body image and depression in tanning behaviors and attitudes. Behav Med. 2012;38(3):74-82. doi:10.1080/08964289.2012.685499

50. Heckman CJ, Munshi T, Darlow S, et al. The association of tanning behavior with psycho-tropic medication use among young adult women. Psychol Health Med. 2016;21(1):60-66. doi:10.1080/ 13548506.2015.1051060
51. Pottegard A, Christensen R, Houji A, et al. Primary non-adherence in general practice: a Danish register study. Eur J Clin Pharmacol. 2014;70(6):757-763. doi:10.1007/s00228-014-1677-y

52. Hafferty JD, Campbell AI, Navrady LB, et al. Self-reported medication use validated through record linkage to national prescribing data. J Clin Epidemiol. 2018;94:132-142. doi:10.1016/j.jclinepi. 2017.10.013

\section{Publish your work in this journal}

Clinical Epidemiology is an international, peer-reviewed, open access, online journal focusing on disease and drug epidemiology, identification of risk factors and screening procedures to develop optimal preventative initiatives and programs. Specific topics include: diagnosis, prognosis, treatment, screening, prevention, risk factor modification,

Submit your manuscript here: https://www.dovepress.com/clinical-epidemiology-journal systematic reviews, risk \& safety of medical interventions, epidemiology \& biostatistical methods, and evaluation of guidelines, translational medicine, health policies \& economic evaluations. The manuscript management system is completely online and includes a very quick and fair peer-review system, which is all easy to use. 